\title{
Tuberculous meningitis: presentation, diagnostic and outcome in HIV-infected individuals from regional center laşi
}

\author{
Andra Teodor ${ }^{1,2^{*}}$, Liviu Jany Prisăcariu2 ${ }^{2}$, Carmen Manciuc ${ }^{1,2}$, Cristina Nicolau ${ }^{1,2}$, Gabriela Jugănariu ${ }^{1,2}$, \\ Dănuț Teodor ${ }^{1,2}$, Carmen Dorobăț, \\ From The 9th Edition of the Scientific Days of the National Institute for Infectious Diseases Prof Dr Matei Bals \\ Bucharest, Romania. 23-25 October 2013
}

\section{Background}

Tuberculous meningitis (TBM) is a growing problem in HIV-infected patients. Our objectives were to analyze the main clinical and laboratory features and immunovirological particularities and outcomes of HIV-infected individuals with TBM.

\section{Methods}

We performed a retrospective study of HIV-infected patients admitted for TBM to the Hospital of Infectious Diseases Iaşi in the last 10 years.

\section{Results}

We registered 21 cases (median age 23, 47\% male), out of which $47 \%$ had pulmonary TB previously. Clinical features were: abrupt onset $57 \%$, headache $47 \%$, fever $66 \%$, vomiting $38 \%$, respiratory symptoms $38 \%$, coma $9.5 \%$, cranial nerve palsy $19 \%$, meningeal syndrome $38 \%$, altered level of consciousness 19\%. Laboratory findings of cerebrospinal fluid: clear aspect $81 \%$, pleocytosis less than $500 / \mathrm{cmm} 66 \%$, protein level more than $1 \mathrm{~g} / \mathrm{L} 91 \%$, glucose level less than $0.4 \mathrm{~g} / \mathrm{L} 71 \%$, decreased chlorine level $57 \%$. Radiologically we found adenopathy in the pulmonary hilum in $24 \%$ of patients. Neurological complications occurred in $24 \%$ and drug related liver toxicity in $33 \%$. We identified $47 \%$ of HIV-infected persons during 1987-1990. The interval between the diagnosis of the HIV-infection and the present hospital admission had a median of 6 years. The median value of the actual CD4 count was $92 / \mathrm{cmm}$ and viral load 570,000 copies $/ \mathrm{mL}$. Prior antiretroviral therapy (ART) was administered in

\footnotetext{
* Correspondence: andrateodor@yahoo.com

1"Gr.T.Popa" University of Medicine and Pharmacy, Iaşi, Romania
}

Full list of author information is available at the end of the article
$80 \%$ of patients with a median of 4 regimens. Only $19 \%$ of the patients were classified as adherent to the ART. The antiretroviral therapy administrated during the present hospital admission was: AZT/3TC + EFV - 9.5\%, $\mathrm{ABC} / 3 \mathrm{TC}+\mathrm{EFV}-9.5 \%, \mathrm{ABC} / 3 \mathrm{TC}+\mathrm{KLT}-4.7 \%$, $\mathrm{ABC}+\mathrm{RAL}+\mathrm{T} 20-4.7 \%$. The median period of hospitalization was 10 days. The overall mortality during hospitalization was $43 \%$ and at 9 months it was $29 \%$. The 9-month survival rate was $28 \%$.

\section{Conclusion}

Immunological and virological failure generated by nonadherence favored the occurrence of TBM. Although the CNS penetration-effectiveness score of the current antiretroviral regimen was above 8 , this did not influence the mortality rate in neuro-meningeal tuberculous infection. In HIV-associated TBM, the clinical course and dismal outcome are undoubtedly influenced by the profound immunosuppression at presentation, emphasizing the need for earlier diagnosis of the HIV infection and initiation of antiretroviral treatment.

\section{Authors' details \\ 1"Gr.T.Popa" University of Medicine and Pharmacy, Iaşi, Romania. ${ }^{2}$ Infectious Diseases Hospital "Sf Parascheva", laşi, Romania.}

Published: 16 December 2013

doi:10.1186/1471-2334-13-S1-P2

Cite this article as: Teodor et al:: Tuberculous meningitis: presentation, diagnostic and outcome in HIV-infected individuals from regional center laşi. BMC Infectious Diseases 2013 13(Suppl 1):P2. 